\title{
Colour as an Element of the Creativity in Education of Design
}

\author{
Zoran Markovic \\ Department of Industrial Design and Technology, University of Botswana, Gaborone, Botswana \\ Email: markovicz@mopipi.ub.bw
}

Received December 2013

\begin{abstract}
Education of Design is creativity based process. From Kansei Engineering to Emotional Design, there are several different approaches in involving feelings and emotions in designing process. Analysing all tools and techniques used by designers, colour has one of the biggest psychological impacts on the final users. Colour has the power not only to change the existing architectural language, but also to be a language on its own. Within architectural semiology, colour has a very important role. The paper presents the preliminary results of the research on cultural background and its influence on the psychological impact of the colour in design (architectural, interior, etc.). The research started in the beginning of 2012 and it has been conducted in Serbia, Botswana, Kenya (fully finalized), India, Slovenia, Brazil (ongoing), Singapore, South Africa and Malaysia (in the preparation stage), Japan, China, Russia, South Korea and Mexico (organization started). The Research objective is to describe, analyse and present importance of the emotional creativity in education, the current status of the role cultural background plays in colour choices in design, as well as to analyse psychological (personal) and social (group) impact and influence of colour. Moreover, the experiments planned are intended not only to outline contemporary cultural influence on colour preferences but also to revisit, revive and expand on the existing research in this field (e.g. [1] Kaya/Epps research at University of Georgia, USA, etc.) by adding the notion of multi-cultural background.
\end{abstract}

\section{Keywords}

Colour, Creativity, Emotion, Education, Design

\section{Introduction}

Today, engineering and design are much more than they used to be. They have transformed into multi-faceted profession(s) under strong influence of areas and disciplines they were not directly connected to in the past. Engineering emerged as a purely technical discipline, partly connected to technical sciences only. Today however, social sciences such as psychology, sociology, and even philosophy, are an integral part of engineering, and especially of design.

When focusing only on technical issues, design and engineering could solve a problem, but can fully satisfy neither the designer/engineer nor the final user. Professor Namagachi [2] defined the concept of Kansei as indi- 
vidual subjective impression which engages all the senses, recognition, balance and emotions and is an integrated part of the engineering and design. In our research, we follow this concept and broaden it by adding the impact of colour to all emotional elements, which are altogether important components of engineering and design.

From another point of view, culture plays a vital role in acceptance of any design product, including architecture design, product design, graphic design, etc. Culture is the basis which we depend upon either consciously or otherwise, for it constitutes a large part of our sense of self-identity in almost everything we do. People generally want to feel a sense of belonging, as well as a degree of affirmation and acceptance by other members of society. Culture has a deep impact on social interaction; it influences among other things, the groups we belong to, our individual lives, our choice of clothes and conduct, as well as the ways in which products are designed and perceived by the users. Design products are considered to be a key medium through which culture is manifested and embodied with respect to the user's cultural background [3] (Brett et al., 1997).

Visual social semiotics as a discipline involves the descriptions of semiotic resources, i.e. what can be said and done with images and other visual means of communication and how the things people say and do with images can be interpreted [4] (Jewitt \& Oyama, 1990: 136). Visual semiotics, according to [5] Roland Barthes (1977), studies only images on their own by asking two fundamental questions: the question of representation (what do images represent and how?); and the question of "hidden meanings" of images (what ideas and values do people, places, and things represented in images stand for?). Social semiotics is closely associated with discourse analysis, visual communications, as well as cultural studies and anthropology, to name but a few - it is a "theory of how people make meaning" in social contexts [6] (Lemke, 1990: 186). Additionally, analyses on how meanings are constructed through the use of systems of social meaning-making, resources vary from one community to another [7] (Wright \& Forrest, 2007). Visual social semiotics stresses that an image or other visual means of communication is not the result of a singular, isolated, creative activity, but it is itself a social process. Social processes are those activities, actions, and operations that involve human interactions.

This paper presents the research of cultural background and psychological influence of colour in design (including architectural design, interior design, product design, etc.). The main goal of the research is to show and to prove whether this impact exists and how strong it is, as well as how strong the influence of cultural background within this impact is.

After more than a year of preparations, the research started in the beginning of 2012 and it has been conducted in Serbia, Botswana, Kenya, (fully finalized), India, Slovenia, Brazil (ongoing), Singapore, South Africa and Malaysia (in the preparation stage). Further research conducting is now being negotiated with Universities in Russia, South Korea, Japan, China, Australia and the USA.

\section{Research Project}

\subsection{Research Question}

The main question is whether and to what extent the cultural background affects the impact colours have in interior design. The research is based on the hypothesis that the cultural background influence is indeed strong, and that the psychological impact of colour is different in every cultural circle which we are analyzing. The research is analyzing both approaches/categories of the culture-objective and subjective [8] (Triandis, 1972), and the ways in which they influence our understanding of colours. Accepting polycentrism of today's culture, the research team tried to analyze and compare results from different cultural circles. Also we had to accept and work with the culture in its multifaceted nature.

Going into further elaboration, our hypothesis could be developed towards prevailing gamma in these areassandy/earthy colours prevailing in Botswana; strong and vibrant colours prevailing in Kenya; white and grey/ light blue colours prevailing in Serbia; etc. Through experiments, we are examining whether our hypothesis is right or wrong. If it proves right, it will be great breakthrough. Interior designers and even paint manufacturers would be able to use these results in everyday practice. Also, it would open a new research field focusing on the relation between colour and cultural background. The results would be empirical and exact, showing psychological influence of particular colours and cultural backgrounds in numbers (percentage, etc.). But before starting to analyze cultural influence, we have to prove the existence and the strength degree of colour impact on a user/visitor in a particularly designed interior. And, as usual, answers to these main questions will come in the end. Only after completing the analyses of all collected data, we will be able to list and describe these impacts and 
1influences. Throughout this project, we have to have in mind that we are going into unexplored area, as this area of research still is not fully established.

\subsection{Main Goals}

The research is aimed at estimating, describing, proving and presenting current situation regarding cultural background influence on colour in interior design and to analyze psychological (personal) and sociological (group) impact of colour. Planned experiments would prove or disprove preliminary research hypothesis and expand on already existing experiments by introducing the multi-cultural background. In order to estimate, prove, describe and present contemporary cultural influence on colour impact—from psychological to sociological—it is necessary to revisit, draw from and renew previous research in this area [1] (Kaya/Epps, 2004).

\section{Project Methodology}

For this research we are using the Mixed method (combined Qualitative and Quantitative methods, both emerging and predetermined approaches, both open and closed-ended questions, and both quantitative and qualitative data and analyses). Research sub-teams would collect both quantitative and qualitative data and use them for the best understanding of research problems. The data collection would involve gathering both numeric information, as well as text information, so the final database will represent both qualitative and quantitative information. Number of the same type of emotional impact will go parallel to analyzing particular type/colour, along with recording of all the details.

The project is planned as to be executed in several countries and all sub-teams would follow the same procedure. The research started with literature review and contacts with established researchers in this field. The research team is planning to use the existing results from similar research as reference points, and to compare our results with them. After considering the potential problems, questions and answers, data collecting started. Experiments would be separated in two stages. The first stage consists of establishing (for each country/cultural circle separately) whether the cultural background affects the psychological impact colours have on users/visitors in interior design. This is the most critical point of the whole project, as at this point research hypothesis has to be proved or disapproved. If this influence and impact are found to be strong enough as to be measured and analyzed, we would continue forward. Distribution of these results would be done in this stage. In the second stage, the emotional stress to body physiology (under influence of the different colours) would be measured. Here, the emotional impact made by different colours will be analyzed, not only by measuring the force of the impact, but also its quality and kind. The finalization of the second stage would be based on computing the results of physiological impact, comparing the results of all the different sub-teams and providing the conclusions so that the distribution process of collected data regarding physiological impact could start.

The main sources of data collecting are interviews with volunteers/informants. To collect good and useful data, the informants have to come from the similar groups. More importantly, the research tools have to be similar in every country. All research tools are divided into two groups-for the preliminary interview and for the final interview.

During the preliminary research, we collect data on generally prevailing colours in each country/cultural circle. In this group, there are $30 \mathrm{~cm}$ rulers, brushes, crayons and folders, all of them given in six basic colours.

The main part of the interview consists of comparing associations, emotions and intensity of the colours, in relation to informant's feelings and understanding. For the main part of the interview, the research team was using paper cards in 6 basic colours (3 primary and 3 secondary), 6 light tinted basic colours, 3 gray scale colours (white, gray and black), and 5 different colour combinations. The most critical element of this part is that all research teams will have the very same colours ("My blue has to be everybody's blue").

Psychological experiment would be executed as an interview supported by a questionnaire. Informants (students-volunteers) would answer questions regarding emotions evoked by different colours and colour combinations. The colour samples and questions would be exactly the same for each sub-team, so that the results could be easily compared. Physiological experiments would be organized after the first stage (psychological interviews) is completed, i.e. after the results are presented and scientifically approved.

\section{Preliminary Results and Conclusion}

Preliminary results are finalized for the first group of the countries-Botswana, Serbia and Kenya. The results are very much as expected and within the research hypotheses. Although the preliminary results show similari- 
ties, they still vary to some extent in all three countries. The most prevailing colours are red and blue. But the percentage, balance of other colours and even the most prevailing colours still vary. Looking only at the preliminary result, we could conclude that the research hypothesis is proved.

One of the main benefits of this research is the analysis of colour as visual language in design. It not only proves the use of colour as a distinct and very important mode of the language, but it also shows the existence of many of its "dialects". Almost every country has its own colour language with different meanings, language which could be understood only within a specific cultural circle. To translate one colour language to another, we have to know and understand both of them. We have to speak them fluently. Thus, a new dimension in colour semiology is being introduced.

The research is still in process and we expect full and final research results during 2014.

\section{References}

[1] Kaya, N. and Epps, H.H. (2004) Color-Emotion Associations: Past Experience and Persdonal Preference. Proceedings of the AIC 2004 Color and Paints, Interim Meeting of the International Colour Association.

[2] Namagachi, M. (2010) Kansei/Affective Engineering. CRC Press, Boca Raton.

[3] Brett, J.M., Tinsley, C.H., Janssens, M., Barsness, Z.I. and Lytle, A.L. (1997) New Approaches to the Study of Culture in Industrial Organizational Psychology. New Lexington Press, San Fransisco.

[4] Jewitt, C. and Oyama, R. (1990) Visual Meaning: A Social Semiotic Approach. A Hand Book of Visual Analysis. In: Van Leeuwen, T. and Jewitt, C., Eds., Sage Publications, London, 134-136.

[5] Barthes, R. (1964/1977) Rhetoric of the Image. Letee’s Island Books, New Haven, Connecticut.

[6] Lemke, J. (1990) Talking Science: Language, Learning and Values. Ablex Publishing Corp, Norwood.

[7] Wright, J. and Forrest, G. (2007) A Social Semiotic Analysis of Knowledge Construction and Game Centered Approaches to Teaching. http://ro.uow.edu.au/era/423/

[8] Triandis, H.C. (1972) Analysis of Subjective Culture. Jstor.org.

[9] Adams, F.M. and Osgood, C.E. (1999) A Cross-Cultural Study of the Affective Meaning of Color. Journal of CrossCultural Psychology, 7, 135-157.

[10] Banks, A. and Fraser, T. (2004) The Complete Guide to Colour/The Ultimate Book for the Colour Conscious. Ilex, Lewes, East Sussex, UK.

[11] Ainsworth, R.A., Simpson, L. and Cassell, D. (1993) Effects of Three Colors in an Office Interior on Mood and Performance. Perceptual \& Motor Skills, 76, 235-241. http://dx.doi.org/10.2466/pms.1993.76.1.235

[12] Choungourian, A. (1968) Color Preference and Cultural Variation. Perceptual \& Motor Skills, 26, 1203-1206. http://dx.doi.org/10.2466/pms.1968.26.3c.1203

[13] Ballast, D.K. (2002) Interior Design Reference Manual. Professional Pub. Inc., Belmont.

[14] Pile, J.F. (1999) Color in Interior Design. The McGraw/Hill Companies, USA.

[15] Rompilla, E. (2005) Color for Interior Design. The New York School of Interior Design. Harry N. Abram, New York.

[16] Press, M. and Copper, R. (2003) The Design Experience: The Role of Design and Designers in the Twenty First Century. Ashgate, Aldershot. 